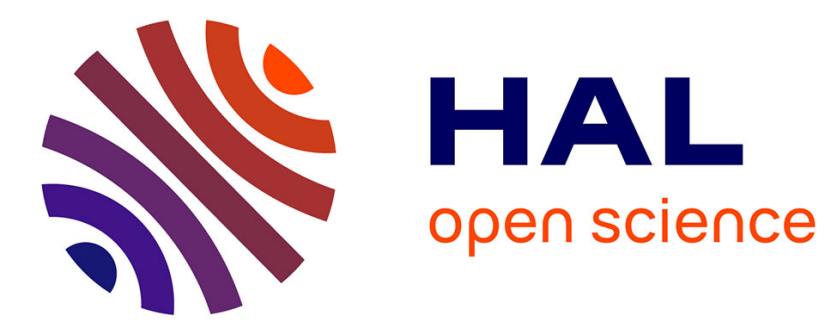

\title{
ACTIVE CENTER TAP QUENCH PROTECTION
}

R. Smits, P. Eberhard, G. Gibson, M. Green, F. Kirsten, R. Ross, P. Salz, James Taylor

\section{To cite this version:}

R. Smits, P. Eberhard, G. Gibson, M. Green, F. Kirsten, et al.. ACTIVE CENTER TAP QUENCH PROTECTION. Journal de Physique Colloques, 1984, 45 (C1), pp.C1-653-C1-657. 10.1051/jphyscol:19841132 . jpa-00223603

\section{HAL Id: jpa-00223603 https://hal.science/jpa-00223603}

Submitted on 1 Jan 1984

HAL is a multi-disciplinary open access archive for the deposit and dissemination of scientific research documents, whether they are published or not. The documents may come from teaching and research institutions in France or abroad, or from public or private research centers.
L'archive ouverte pluridisciplinaire HAL, est destinée au dépôt et à la diffusion de documents scientifiques de niveau recherche, publiés ou non, émanant des établissements d'enseignement et de recherche français ou étrangers, des laboratoires publics ou privés. 


\title{
ACTIVE CENTER TAP QUENCH PROTECTION*
}

\author{
R.G. Smits, P.H. Eberhard, G.H. Gibson, M.A. Green, F. Kirsten, R.R. Ross, \\ P. Sa1z and J.D. Taylor \\ Lawrence Berkeley Laboratory, University of California, Berkeley, \\ Califomia 94720 , U.S.A.
}

\section{RESUME}

Le solénoïde supraconducteur de $2 \mathrm{~m}$ de diamètre pour le "Time Projection Chamber" (TPC) est protégé par un système de protection de quench actif consistant à décharger une capacité au point milieu de 1'aimant. L'énergie stockée dans le condensateur est déchargée entre les deux couches de la bobine afin de 1a faire transiter à l'état normal. De cette façon l'énergie de 1'aimant est dissipée plus uniformëment dans la bobine et dans ses circuits secondaires. Cet article décrit la méthode de protection de quench utilisée pour I'aimant TPC.

\section{ABSTRACT}

The two-meter-diameter superconducting solenoid for the Time Projection Chamber (TPC) experiment is protected by an active quench protection system which discharges a capacitor into the center tap of the magnet. The energy stored in the capacitor is discharged between the two layers of the superconducting coil to drive it normal. Thus the magnet energy is deposited in the coil and its secondary circuits more uniformly. This paper describes the quench-protection method as used on the TPC magnet.

\section{Introduction}

The $1.5 \mathrm{~T}$ superconducting solenoid magnet for the Time Projection Chamber (TPC) particle detector at PEP is about 2.2 meters in diameter by 3.3 meters long, and stores $10 \mathrm{MJ}$ of magnetic energy. The coil operates at $2260 \mathrm{~A}$ with a current density of $600 \mathrm{~A} / \mathrm{mm}^{2}$ in the wire. The wire consists of $\mathrm{Nb}-\mathrm{Ti}$. filaments in a rectangular copper matrix.

To prevent burnout during a quench, active quench protection is employed. A quench-detector, constant1y monitoring the operating magnet detects that a small amount of superconducting wire has turned resistive, and triggers the protection system which injects a high current pulse into the center-tap of the coil causing enough heating to turn much of the solenoid normal. The protection system works by spreading the resistive region throughout the coil. The current is quickly reduced because the magnet also employs "shorted-secondary" windings. The stored energy is dissipated as heat within the cryostat.

An advantage of this system is that high voltages exist only during the time when the vacuum is cryogenically pumped (and, therefore, electrical breakdown in gases cannot easily occur) because the protection pulse lasts less than 20 milliseconds. This technique contrasts with systems which switch the magnet current into an external resistor and have high terminal voltages for longer times.

\footnotetext{
* This work was supported by the Director, Office of Energy Research, Office of High Energy and Nuclear Physics, Division of High Energy Physics of the U.S. Department of Energy under Contract No. DE-AC03-76SF00098.
} 
II. Magnet Characteristics

The center tap quench protection system is aided by the following special characteristics built into the coil. See Fig. 1.

1) The superconducting coil is wound in two layers, each with the same number of turns. The center-tap connection is made where the superconductor changes layers. Close inductive coupling results between the halves of the superconducting coil, which maximizes the current obtained from the pulser for a given voltage, and increases the heating so the superconductor will easily turn normal.

2) The high current density in the wire of the magnet reduces the heat capacity of the superconductor and, therefore, decreases the pulse current required to turn the coil normal.

3) Close inductive coupling to a shorted, low resistance pure copper winding (UPC) helps reduce the superconductor current after the protection pulse and minimizes the energy which must be dissipated in the superconducting coil after it turns normal.

4) The coil-form is a "shorted turn" of low resistivity aluminum and it will absorb most of the energy after the superconductor turns normal. It has enough heat capacity to prevent its final temperature from exceeding $200 \mathrm{~K}$.

5) The TPC magnet operates in vacuum instead of a liquid helium bath. It is cooled by heat conduction to a heat exchanger tube carrying two phase helium. Therefore, the superconductuctok can be heated easily by the center-tap pulse.

6) Electrical insulation between all the layers provides sufficient spacing to withstand the voltage of the center tap pulse at cryogenic temperature even if the insulation is cracked.

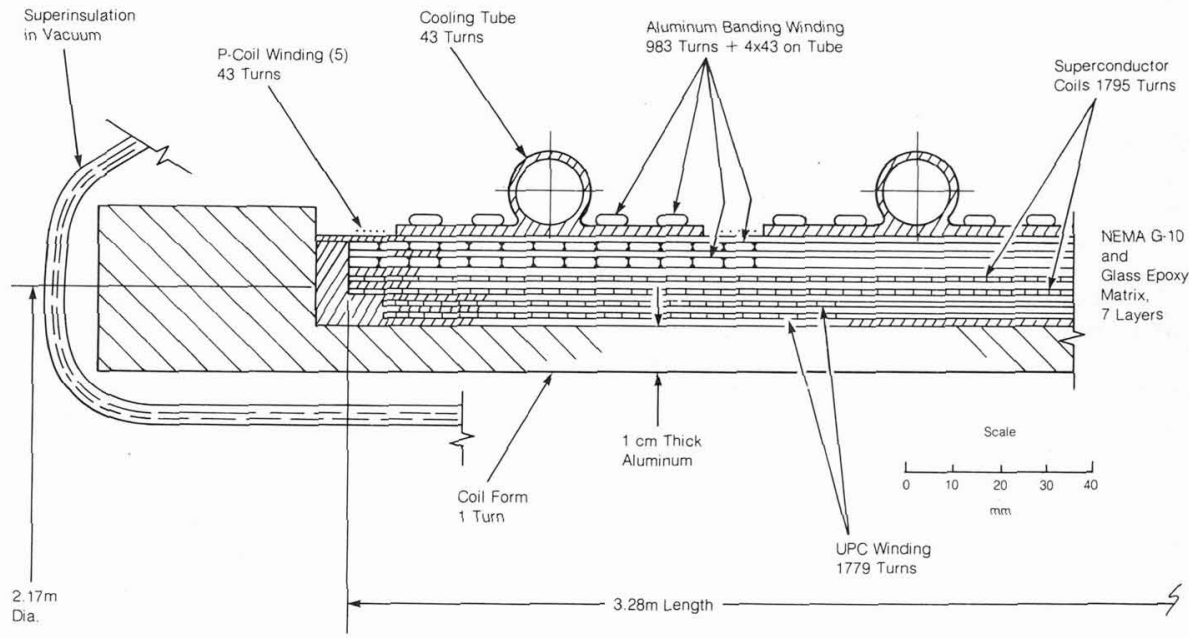

Fig. 1 - TPC magnet construction

\section{Protection Circuit}

Figure 2 shows schematically the essential features of the center-tap quench-protection system. An auxiliary power supply charges the capacitor bank (C) via a resistor (R) which protects the power supply during the pulse. The return connection is through the superconducting winding. 


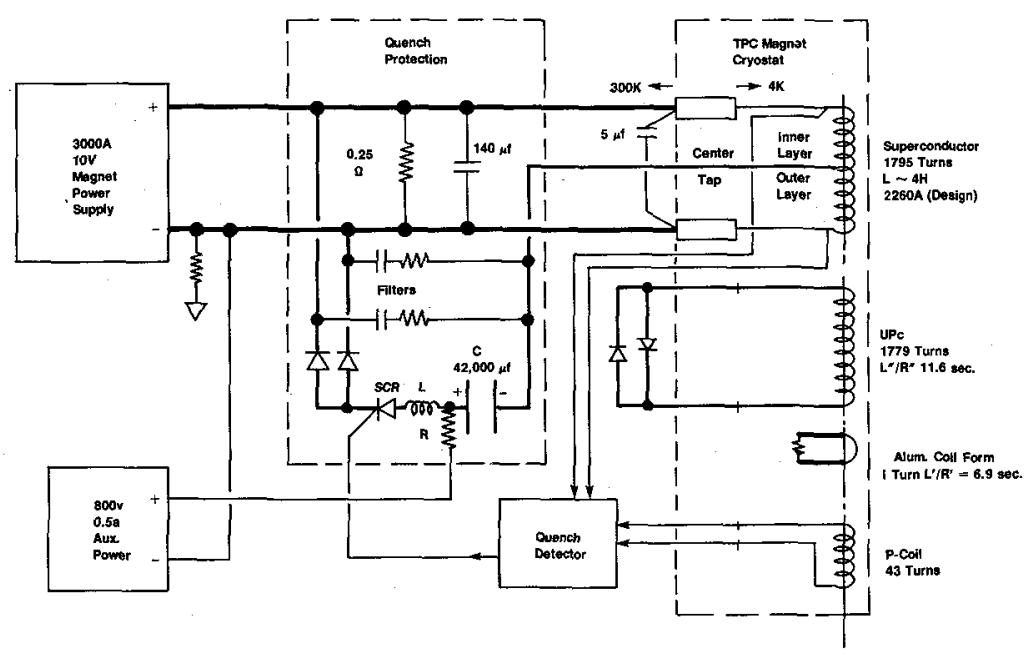

Fig.2 - Power and protection circuit.

When the quench detector determines that some of the superconductor has turned resistive, it fires the SCR which discharges the capacitor's energy via diodes to both magnet leads delivering a negative 800-volt pulse to the center tap. If the protection circuit is fired when no current is flowing in the coil, the protection current is approximately equally (1.2 to 1 ratio) divided between the two layers. If current is flowing in the coil, the protection pulse increases the current in one layer and decreases it in the other. The net effect is a large change in magnetic field between the windings and virtually no change in the magnetic field anywhere else. The field change heats the superconductor and the copper matrix of the superconducting wire.

There is $800 \mathrm{~V}$ on the electrolytic capacitor bank. The capacitor bank consists of 360 capacitors in groups of four capacitors in series-forward polarity so they operate at only $200 \mathrm{~V}$ each but charge backward during the last half of the pulse. The sustained very low polarizing voltage is predicted to enhance their lifetime and the brief reverse charging is not harmfu1. The final rating of the entire capacitor bank would then be $36 \mathrm{mf}$ (measured $43 \mathrm{mf}$ ) at $1800 \mathrm{~V}$. The air core inductor L in Fig. 2, together with the total resistance of the circuit, limits the rate of increase of current to

$33 \mathrm{~A} / \mathrm{us}$ and the peak current to $8000 \mathrm{~A}$, the ratings for the SCR. There is also an SCR limit for $\int i^{2} d t$ in the $\mathrm{SCR}<265000 \mathrm{~A}^{2} \mathrm{~s}$.

Finally, it is necessary to protect the magnet from fast voltage transients that might otherwise produce large turn-to-turn voltages. The two $\mathrm{r}-\mathrm{c}$ filters between the center tap and the coil-end connections smooth the initial firing pulse. Other small capacitors across the coil terminals intercept higher frequency components that cannot be stopped by the $\mathrm{r}-\mathrm{c}$ filters which, because of their size, are too far away.

\section{Results of the Coil Test Without Iron}

During the first testing phase of the TPC solenoid, the coil was operated with the protection circuit of Fig. 2. The quench protection did not trigger when the coil was powered at full current but a spurious triggering of the quench-protection system at $97 \%$ of design current (without an actual quench) gave us the data for Figs. 3-5. 


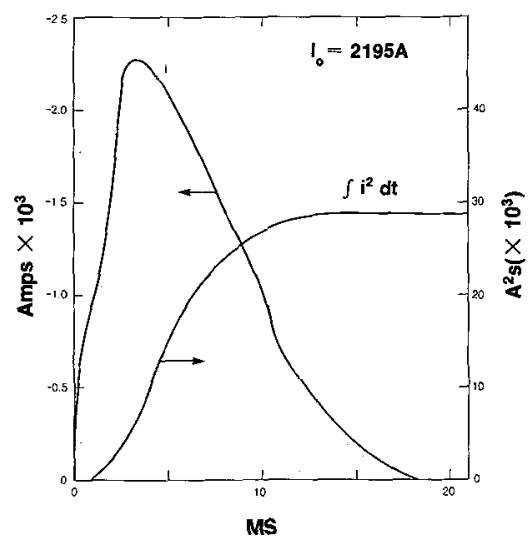

Fig. 3 - Protection pulse.

Figure 3 shows the current pulse from the center tap lasting less than 20 ms. The peak current is only $2300 \mathrm{~A}$ and the $\int \mathrm{i}^{2}$ dt is $28700 \mathrm{~A}^{2} \mathrm{~s}$.

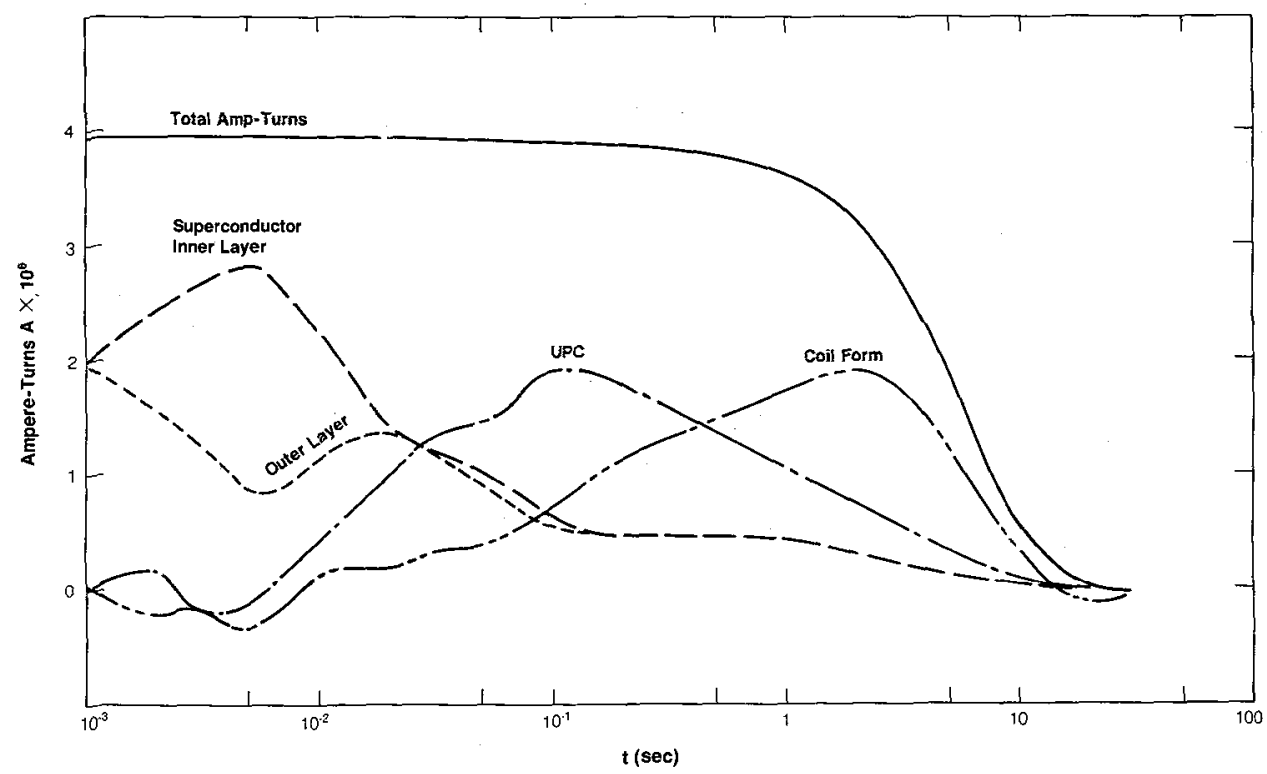

Fig. 4 - Current distribution.

Figure 4 shows that the negative pulse to the coil center-tap (with normal magnet polarity) increases the current through the inner layer of the coil. The inner layer turns normal before its current reaches the critical current. It remains normal because of joule heating of the wire by the magnet current. The outer layer turns partially normal by eddy-current heating, and later entirely normal by. heat conduction from the inner layer. When the superconductor turns normal, the total magnet flux drops slightiy, inducing currents in the UPC and the coil-form. Just after the pulse, the UPC ampere-turns increase most because the UPC $\mathrm{L} / \mathrm{R}$ time-constant is longest. Later, when the UPC warms up, its resistance rises causing a decrease in UPC current and an increase in the coil-form current. 


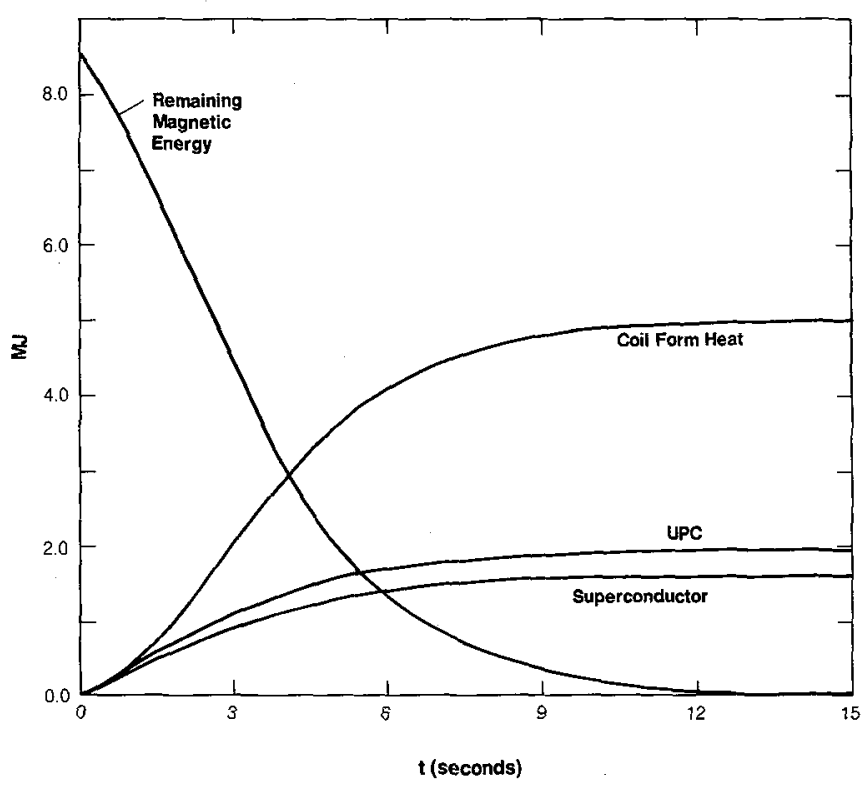

Fig. 5 - Energy distribution.

Figure 5 shows where the energy is deposited throughout the various windings of the coil package. The hottest possible spot in the superconductor can be no warmer than $200 \mathrm{~K}$ because the $\int i^{2}$ dt from $20 \mathrm{~ms}$ before the time of firing of the protection system to time of zero current was only $0.9 \times 10^{6}$ $\mathrm{A}^{2} \mathrm{~s}$. The extra $20 \mathrm{~ms}$ is included to simulate the time required for quench detection to occur. 2

Essential parts of the active quench protection system, not covered by this report, include the quench detector, non-interruptable power for the quench-detection/protection systems, and safety interlocks for personnel protection.

\section{Acknowledgments}

The authors are indebted to the SLAC refrigeration crew for quench-proofing the liquid helium system, to Kevin Derby for data gathering and analysis programs, and to Frank Petro for electronic installation.

\section{References}

1. HOPKINS,D.B., IRE Trans. on Nuclear Science NS.9:N0.2 April 1962 UCRL 9968.

2. EBERHARD, P.H. et al., Nuclear Instruments and Methods 158 (1979) 33-40. \& Methods 158 (1979) 33-40. 